\title{
Oral Manifestations in COVID 19
}

\author{
Stefania $\mathrm{M}^{*}$ and Carnovale G \\ University of Palermo, Italy
}

*Corresponding author: Morici Stefania, University of Palermo, Italy, Tel: 3200653008;

Email: studiodentisticomorici@gmail.com
Investigation Paper

Volume 5 Issue 4

Received Date: October 12, 2020

Published Date: October 23, 2020

DOI: $10.23880 /$ oajds- 16000273

\section{Abstract}

Clinical evidence has shown Covid-19 is not tipically confined to the respiratory tract but can be a multi-organ virus and affect the CNS (Central Nervous System) with specific symptoms such as vomiting, diarrhea, headache as well as the PNS (Peripheral Nervous System) with neuralgia, hypogeusia, systemic dermal vasculitis especially in the lower limbs, gluteal muscles and MOUTH. These manifestations all have a specific inflammatory picture.

Keywords: Oral Manifestations; COVID-19

\section{Introduction}

Viruses are special biological entities capable of invading an organism, proliferate and self-adjust with cell- binding by eluding the defenses of membranes and modifying the cells' genetic features. On January 30th WHO declared the state of pandemic from Covid-19 new Coronavirus. It is an RNA virus which can codify and modify genetic information: the $S$ glicoprotein on the virion surface binds to the ACE2 receptor, which is a necessary step for the virus to access human cells. It is transmitted by air (saliva and droplets from coughing and sneezing). Its incubation period ranges from 2 to 14 days. Common clinical manifestations include fever, cough, fatigue, shortness of breath, with a tendency of the disease to develop into pneumonia. Its radiological picture is similar to other viral types of pneumonia, with the most characteristic symptom being respiratory distress. Blood sample analysis results in most patients show normal WBC, reduced lymphopenia and a higher count of neutrophil granulocytes. Innate immunity shows the activation of some cytokines and chemochines, among which IL-1/IL-2/IL-7/ IL-13/IL-17, stimulators of macrophages, y interferon, 1protein of monocytes, $1 \mathrm{a}$ anti-inflammatory protein and TNF (tumor necrosis factor) [1-5].

Clinical evidence has shown Covid-19 is not tipically confined to the respiratory tract but can be a multi-organ virus and affect the CNS (Central Nervous System) with specific symptoms such as vomiting, diarrhoea, headache as well as the PNS (Peripheral Nervous System) with neuralgia, hypogeusia, systemic dermal vasculitis especially in the lower limbs, gluteal muscles and MOUTH. These manifestations all have a specific inflammatory picture. Viral traces have been detected in all kinds of human tissue, faeces, glomerular filtrate and saliva, where the viral charge has resulted in a very high percentage and it appears to persist for more than 28 days. According to patient-history records, clinical and photographic reports the mouth is also a target of Covid-19. Each viral particle in an organism alters the cell turnover of tissues. Covid-19 has been shown to induce virus-like lesions in the mouth and perioral tissues. Specific antigens of histological compatibility have been detected with the outbreak of the new Coronavirus and the disease has been shown to have clinical recurrence in $90 \%$ of cases. A predisposing factor is represented by immunosuppression from viral causes. Covid-19 patients with severe forms of the disease present a circular hyperkeratinization of the epithelium, with blood lysis on the surface, especially major gingival enanthema in both dental arches. As for any oral lesion caused by viral particles, the destruction of the mucose in Covid-19 is due to cytotoxic lymphocytes and to the production of a peculiar TNF cytokine which is a vehicle of infection and results in the lysis of endothelial cells and neutrophil granulocytes. 
Clinically speaking, therefore, the virus replicates in the pulmonary epithelium and hence spreads to the skin and mucous membranes in the form of small erythematous maculo-papulae which break and develop into eruptions covered by crusts. One of the most widespread clinical signs is enanthema of the mouth mucosa, presenting pointlike blisters surrounded by an erythematous halo [6-9]. In some cases, foot-and -mouth -like injuries have been found in the intra-oral mucosa starting as widespread small 1-2 $\mathrm{mm}$ spots which in a few day are joined together to form a single ulcer covered by psedo-membranes on the lip surface. The lips appear swollen, chapped and covered by bleeding eschars turning nechrotic (Figures 1-3), clearly bordered by hard erythematous tissue and fibrin.
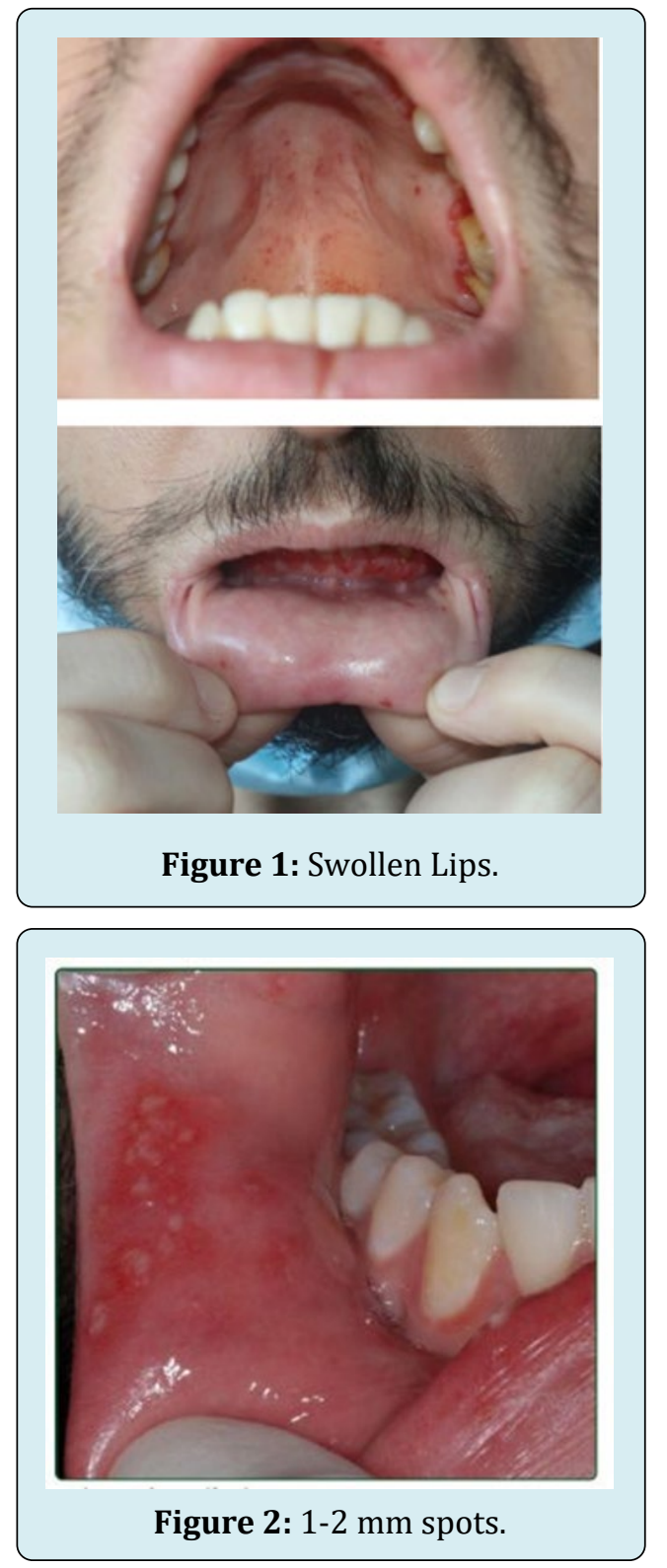

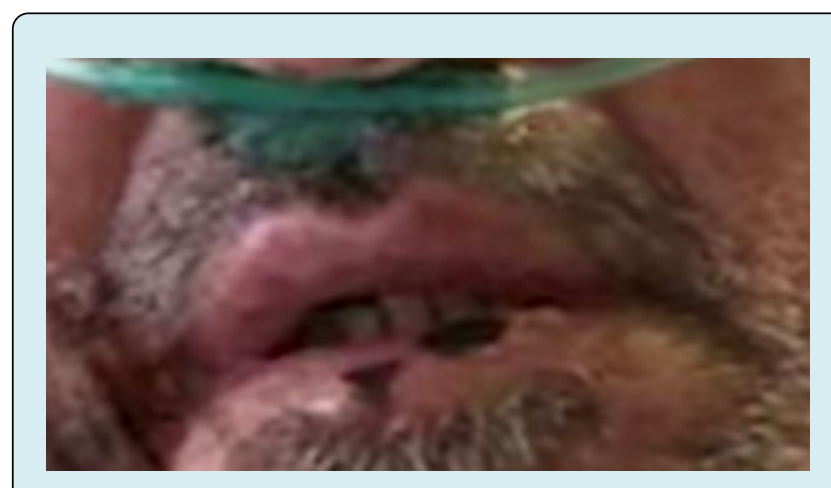

Figure 3: Hard erythematous tissue and fibrin.

Important points for reflection have emerged on the possible effects of drug therapies currently used on Covid-19 patients and the remission of all symptoms and clinical signs also at the mouth level. So Clinical cases of Covid-19 patients kindly supplied by Prof. Cristina Galvan Casas, Universidade de Madrid and the collaboration of Dott. F. Armato, pulmonologist at the Trapani Covid-19 hospital.

\section{References}

1. Mao L, Wang M, Chen S, He Q, Chang J, et al. (2020) Neurological Manifestations of Hospitalized Patients with COVID-19 in Wuhan, China: a retrospective case series study. medRxiv.

2. Li YC, Bai WZ, Hashikawa T (2020) The neuroinvasive potential of SARS-CoV2 may play a role in the respiratory failure of COVID-19 patients. J Med Virol.

3. Lauer SA, Grantz KH, Bi Q, Jones FK, Zheng Q, et al. (2020) The Incubation Period of Coronavirus Disease 2019 (COVID-19) From Publicly Reported Confirmed Cases: Estimation and Application. Ann Intern Med.

4. Wu J, Chen ZJ (2014) Innate immune sensing and signaling of cytosolic nucleic acids. Annu Rev Immunol 32: 461-488.

5. Chen L, Xiong J, Bao L, Shi Y (2020) Convalescent plasma as a potential therapy for COVID-19. Lancet Infect Dis 20(4): 398-400.

6. Zumla A, Chan JF, Azhar EI, Hui DS, Yuen KY (2016) Coronaviruses-drug discovery and therapeutic options. Nat Rev Drug Discov 15(5): 327-347.

7. Li H, Wang YM, Xu JY, Cao B (2020) Potential antiviral therapeutics for 2019 Novel Coronavirus. Chin J Tuberc Respir Dis 43(0): E002 
Open Access Journal of Dental Sciences

8. Agostini ML, Andres EL, Sims AC, Graham RL, Sheahan TP, et al. (2018) Coronavirus susceptibility to the antiviral remdesivir (gs-5734) is mediated by the viral polymerase and the proofreading exoribonuclease. mBio 9(2): e00221-18.
9. Italian Council of Ministers, resolution of 31st January 2020. Declaration of National Emergency following the risk of emerging pathologies deriving from transmissible viral agents. Gazzetta Ufficiale Serie Generale n. 26 del $1^{\circ}$ febbraio 2020. 